\title{
Interactive comment on "Establishing relationship between measured and predicted soil water characteristics using SOILWAT model in three agro-ecological zones of Nigeria" by OrevaOghene Aliku and Suarau O. Oshunsanya
}

OrevaOghene Aliku and Suarau O. Oshunsanya

orevaoghenealiku@gmail.com

Received and published: 11 October 2016

The comment was uploaded in the form of a supplement:

http://www.geosci-model-dev-discuss.net/gmd-2016-165/gmd-2016-165-AC2-

supplement.pdf

Interactive comment on Geosci. Model Dev. Discuss., doi:10.5194/gmd-2016-165, 2016. 